\section{One-Year Evaluation of a Simplified Ethanol-Wet Bonding Technique: A Randomized Clinical Trial}

\author{
Joyce Figueira de Araújo, Thais Andrade de Figueiredo Barros, Esther Marina \\ França Braga, Sandro Cordeiro Loretto, Patrícia de Almeida Rodrigues Silva \\ e Souza, Mário Honorato Silva e Souza Júnior
}

Department of Clinical Dentistry, Dental School, UFPA - Federal University of Pará, Belém, PA, Brazil

Correspondence: Prof. Dr. Mário Honorato Silva e Souza Júnior, Travessa Dom Romualdo de Seixas, 156, ap. 501, 66050-110 Belém, PA, Brasil. Tel.: +55-91-3229-7337. e-mail: mario-honorato@hotmail.com
The objective of this randomized clinical trial was to evaluate the clinical performance of adhesive restorations using a three-step etch-and-rinse adhesive (TSER), a one-step self-etching adhesive (OSSE), and a simplified ethanol-wet bonding technique (EWBT) prior to the application of a composite resin in non-carious cervical lesions. Ninety-three restorations ( 31 for each group) were placed in 17 patients by a single operator. No cavity preparation was performed. After 6 and 12 months, the restorations were assessed by two previously trained examiners using modified Ryge criteria for retention (kappa $=1.00)$ and marginal adaptation/staining ( $\mathrm{kappa}=0.81$ ), and the results were analyzed by Fisher's exact and Kruskal-Wallis tests, respectively. No significant differences were observed among groups at the 6 - and 12 -month time points for any of the assessed criteria $(p \geq 0.05)$. The intra-group analysis performed by Cochran's test (for retention) and Wilcoxon test (for marginal adaptation/staining) revealed significant differences between the baseline/12month time intervals in marginal adaptation in OSSE $(p=0.0180)$ and in marginal staining in TSER ( $p=0.0117)$. The survival analysis for retention criteria performed using a logrank test did not show significant differences $(p>0.05)$. The restorations placed using the simplified EWBT performed equally well as the other adhesive strategies employed.
Key Words: randomized controlled trial, dentinbonding agents, dentin.

\section{Introduction}

Despite the immediate in vitro efficacy of adhesive systems, interface failures may occur after a short period $(1,2)$, which may be partially explained by the high hydrophilicity of these systems (3-5). Presence of hydrophilic monomers and incomplete resin infiltration in demineralized dentin by etch-and-rinse technique may increase water sorption and risk of hydrolytic degradation, which may reduce the adhesive mechanical properties over time $(1,6-9)$.

The self-etching (SE) systems eliminate the need for previous acid etching, a critical step for adhesion (10-13). Theoretically, there is no or small difference between the depths of demineralization and resin infiltration induced by this system because both processes occur simultaneously (14-16). However, this adhesive strategy also has high hydrophilicity, which attracts water and compromises adhesive interface integrity $(17,18)$.

The ethanol-wet bonding technique (EWBT) was introduced in an attempt to overcome the problems caused by incomplete penetration of most adhesive systems and the high hydrophilicity observed in commercially available adhesive systems. In EWBT, the dentin is saturated by increasing concentrations of ethanol solutions prior to the application of hydrophobic monomers to produce a more stable and hydrolysis-resistant hybrid layer $(3,5,19)$.

TheEWBT mayreduce the hydrophilic characteristics of the interface. Dentin dehydration occurs with application of increasing concentrations of ethanol solutions, allowing the subsequent infiltration of a hydrophobic primer followed by a hydrophobic adhesive resin $(3,6)$. This hybrid layer is less hydrophilic and more resistant to overtime hydrolytic degradation caused by the endogenous enzymes, such as metalloproteinases (MMPs), due to a more effective collagen protection $(19,20)$ and prevention of phase separation $(8,18,21,22)$.

Some laboratory studies demonstrated higher adhesive interface bond strengths when ethanol solutions were used to dehydrate dentin prior to primer and adhesive application, compared with the strengths achieved using conventional adhesive techniques $(4,7,18,21)$. However, there is lack of clinical data for this strategy.

The objective of this randomized study was to evaluate the clinical performance of restorations in non-carious cervical lesions (NCCL) using a simplified EWBT compared with the three-step etch-and-rinse and one-step SE approaches for up to 12 months. The tested null hypothesis was that there are no differences in clinical behavior (retention and marginal adaptation/staining) among the three adhesive techniques.

\section{Material and Methods}

This single-center, randomized controlled clinical trial 
was conducted at the Federal University of Pará, Brazil and was approved by the Ethics Committee on Investigations Involving Human Subjects at the Federal University of Pará (UFPA). This study was designed following the main guidelines of the CONSORT Group (Consolidated Standards of Reporting Trials) and was registered at the ISRCTN (International Standard Randomized Controlled Trial Number) under the number 00627732.

The retention rate (100\%) of two adhesive systems at five years (23) was used as a parameter for sample size calculation. In order to detect a 20\% difference among groups with $80 \%$ power and a significance level of 5\%, the minimal sample size should be 31 restorations per group.

Initially, 48 volunteer patients (employees and students) of the UFPA who were interested in this research were evaluated and 17 of them, with ages ranging from 23 to 54 years old, were ultimately enrolled. They were instructed on the conditions and objective of the study and signed an informed consent form prior to participating. Eligibility criteria were: good oral hygiene, no periodontal disease and at least 3 NCCLs. Exclusion criteria were the presence of an orthodontic appliance or partially removable prosthodontics, high caries risk (presence of three or more active caries lesions), heavy bruxism and patients who did not accept the conditions of the project.

Each patient received at least 3 or multiple of 3 restorations. Each adhesive system was randomly allocated to one of randomized cervical lesions until the three groups were present in the same subject and in equal amounts.

A total of 93 NCCLs (31 for each group) were restored by one experienced operator using three types of adhesive strategies: Adper Scotchbond Multi-Purpose/SBMP (threestep etch-and-rinse adhesive - TSER; 3M ESPE, St. Paul, MN, USA); Adper Easy One/EO (one-step self-etching adhesive - OSSE; 3M ESPE, Seefeld, Germany); and simplified etanolwet bonding technique - EWBT (dentin saturation with ethanol solutions + hydrophobic experimental primer + step 3 of SBMP - 3M ESPE). The hydrophobic primer used in the EWBT was prepared by diluting $2 \mathrm{~mL}$ step 3 of SBMP (3M ESPE) in absolute ethanol corresponding to $10 \%$ mass.

Table 1. Adhesive compositions and instructions for use

\begin{tabular}{ll}
\hline Material Adhesive technique & Ad
\end{tabular}

Adper Scotchbond

Multi-Purpose + Filtek ${ }^{\mathrm{TM}}$

Z350 XT (3M ESPE)

Adper Easy One + Filtek ${ }^{\mathrm{TM}}$

Z350 XT (3M ESPE)

EWBT:

experimental

"hydrophobic primer"

+ step 3 of Adper

Scotchbond Multi-

Purpose + Filtek ${ }^{\mathrm{TM}}$

Z350 XT (3M ESPE)
1- etching of enamel and dentin for $15 \mathrm{~s}$, with 35\% phosphoric acid gel and rinsing by air-water spraying for $30 \mathrm{~s}$ 2- dentin blotting with absorbent paper to keep the surface visibly moist 3- application of primer to enamel and dentin. Dry gently for $5 \mathrm{~s}$ 4- application of adhesive and light curing for $10 \mathrm{~s}$ 5- restoration with $\cong 1-\mathrm{mm}$ layers of FiltekTM Z350XT

1- dentin washing and blotting with absorbent paper to keep the surface visibly moist

2- application of Easy One adhesive for $20 \mathrm{~s}$, air-drying for $5 \mathrm{~s}$ and light curing for $10 \mathrm{~s}$ 3 - restoration with $\cong 1-\mathrm{mm}$ layers of Filtek ${ }^{\mathrm{TM}} \mathrm{Z} 350 \mathrm{XT}$

Table 2. Restorations distribution

\begin{tabular}{|c|c|c|c|c|c|c|c|c|c|}
\hline \multirow[b]{2}{*}{ Arch } & \multirow{2}{*}{$\begin{array}{c}\text { Adhesive } \\
\text { system group }\end{array}$} & \multicolumn{4}{|c|}{ Right quadrant (45) } & \multicolumn{4}{|c|}{ Left quadrant (48) } \\
\hline & & $\begin{array}{c}\text { Molar } \\
\text { (7) }\end{array}$ & $\begin{array}{c}\text { Premolar } \\
\text { (27) }\end{array}$ & $\begin{array}{c}\text { Canine } \\
\text { (3) }\end{array}$ & $\begin{array}{c}\text { Incisor } \\
\text { (8) }\end{array}$ & $\begin{array}{l}\text { Molar } \\
(10)\end{array}$ & $\begin{array}{c}\text { Premolar } \\
\text { (29) }\end{array}$ & $\begin{array}{l}\text { Canine } \\
\text { (5) }\end{array}$ & $\begin{array}{c}\text { Incisor } \\
\text { (4) }\end{array}$ \\
\hline \multirow{3}{*}{$\begin{array}{l}\text { Maxilla } \\
(52)\end{array}$} & TSER (18) & 0 & 6 & 1 & 3 & 2 & 4 & 1 & 1 \\
\hline & OSSE (17) & 3 & 1 & 0 & 3 & 1 & 8 & 1 & 0 \\
\hline & EWBT (17) & 1 & 7 & 2 & 0 & 3 & 3 & 1 & 0 \\
\hline \multirow{3}{*}{$\begin{array}{l}\text { Mandible } \\
\text { (41) }\end{array}$} & TSER (13) & 1 & 1 & 0 & 1 & 1 & 8 & 1 & 0 \\
\hline & OSSE (14) & 0 & 6 & 0 & 0 & 1 & 4 & 1 & 2 \\
\hline & EWBT (14) & 2 & 6 & 0 & 1 & 2 & 2 & 0 & 1 \\
\hline
\end{tabular}

( ) total number of restorations. TSER: Three-step etch-and-rinse adhesive. OSSE: One-step self-etching adhesive. EWBT: Simplified ethanol-wet bonding technique. 
All restorations were placed under relatively dry conditions using gingival retraction cord, cotton rolls and saliva ejector. Enamel margins were not beveled and no mechanical retention was performed. The surfaces were slightly roughened with a \#3118 diamond bur (K.G. Sorensen, São Paulo, SP, Brazil).

After adhesive systems application, the cavities were restored by applying at least two layers of Filtek Z350 XT (3M ESPE), light-cured for 40 s using a light-emitting diode (LED) unit (D-2000; DMC, Joinvile, SC, Brazil) at $1100 \mathrm{~mW} / \mathrm{cm}^{2}$. Restorations were polished with \#3195 fine diamond burs (K.G. Sorensen) and candle flame rubber points (Dentsply/ Caulk, Milford, DE, USA). Table 1 lists the materials and techniques used for each group, and the distribution of the restorations with respect to tooth type, adhesive, quadrant and arch are shown in Table 2.

Two calibrated examiners evaluated all restorations using the modified US Public Health Service guidelines (USPHS). In cases where the two examiners disagreed on a rating, both re-examined the restoration and arrived to a joint final decision. The examiners were blinded regarding the type of adhesive used in each restoration. The primary outcome was retention $(\mathrm{kappa}=1.00)$, with marginal adaptation/staining (kappa $=0.81$ ) as secondary outcome, both analyzed at 6 and 12 months.

The obtained data were recorded and the differences among adhesive systems at each evaluation period were analyzed using Fisher's exact test for retention and the Kruskal-Wallis test for marginal adaptation/staining at a $5 \%$ significance level. An intra-group comparison among baseline, 6- and 12-month evaluation for each adhesive system was performed using Cochran's test (for retention) and the Wilcoxon test (for marginal adaptation/staining) at a 5\% significance level. At baseline, all restorations were scored A for all evaluation criteria. The survival analysis for retention criteria was performed using a log-rank test at a $5 \%$ significance level. survival curves for adhesive systems and $p$ values.

From the intra-group analysis that assessed the behavior of each adhesive system over time, significant differences were detected between baseline and 12 months in marginal adaptation in OSSE and marginal staining in TSER groups (Table 4).

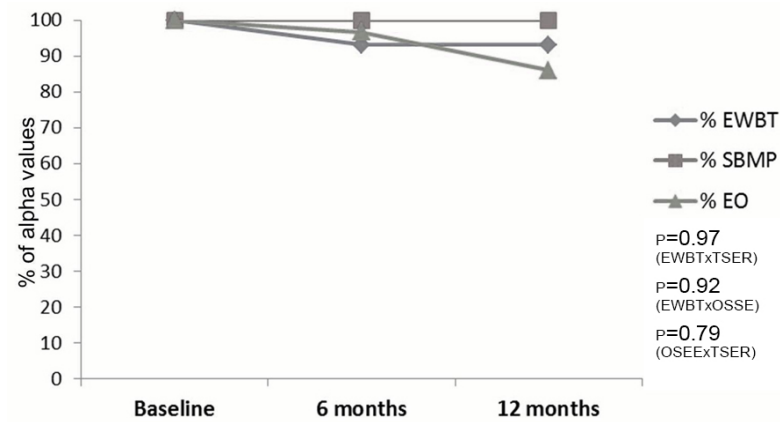

Figure 1. Survival curves for each adhesive system for up to 12 months.

Table 3. Clinical evaluation for each criterion at 6 and 12 months

\begin{tabular}{|c|c|c|c|c|c|c|c|}
\hline \multirow{2}{*}{ Criteria } & \multirow{2}{*}{$\begin{array}{l}\text { Adhesive } \\
\text { system } \\
\text { group }\end{array}$} & \multicolumn{3}{|c|}{6 months } & \multicolumn{3}{|c|}{12 months } \\
\hline & & A & B & C & A & B & C \\
\hline \multirow{7}{*}{ Retention } & \multirow{7}{*}{$\begin{array}{l}\text { TSER } \\
\text { OSSE } \\
\text { EWBT }\end{array}$} & $31 / 31$ & - & 0 & $31 / 31$ & - & 0 \\
\hline & & $30 / 31$ & - & $1 / 31$ & $27 / 30$ & - & $3 / 30$ \\
\hline & & $29 / 31$ & - & $2 / 31$ & $29 / 29$ & - & 0 \\
\hline & & \multirow{4}{*}{\multicolumn{3}{|c|}{$\begin{array}{l}p=1.000(\mathrm{G} 1 \times \mathrm{G} 2)^{\mathrm{a}} \\
\mathrm{p}=1.000(\mathrm{G} 2 \times \mathrm{G} 3)^{\mathrm{a}} \\
\mathrm{p}=0.4918(\mathrm{G} 1 \times \mathrm{G} 3)^{\mathrm{a}}\end{array}$}} & \multirow{4}{*}{\multicolumn{3}{|c|}{$\begin{array}{l}\mathrm{p}=0.1128(\mathrm{G} 1 \times \mathrm{G} 2)^{\mathrm{a}} \\
\mathrm{p}=0.2373(\mathrm{G} 2 \times \mathrm{G} 3)^{\mathrm{a}} \\
\mathrm{p}=1.000(\mathrm{G} 1 \times \mathrm{G} 3)^{\mathrm{a}}\end{array}$}} \\
\hline & & & & & & & \\
\hline & & & & & & & \\
\hline & & & & & & & \\
\hline \multirow{4}{*}{$\begin{array}{l}\text { Marginal } \\
\text { adaptation }\end{array}$} & \multirow{4}{*}{$\begin{array}{l}\text { TSER } \\
\text { OSSE } \\
\text { EWBT }\end{array}$} & $30 / 31$ & $1 / 31$ & 0 & $29 / 31$ & $2 / 31$ & 0 \\
\hline & & $26 / 30$ & $4 / 30$ & 0 & $20 / 27$ & $7 / 27$ & 0 \\
\hline & & $28 / 29$ & $1 / 29$ & 0 & $27 / 29$ & $2 / 29$ & 0 \\
\hline & & \multicolumn{3}{|c|}{$p=0.8763^{b}$} & \multicolumn{3}{|c|}{$p=0.3582^{b}$} \\
\hline \multirow{4}{*}{$\begin{array}{l}\text { Marginal } \\
\text { staining }\end{array}$} & \multirow{4}{*}{$\begin{array}{l}\text { TSER } \\
\text { OSSE } \\
\text { EWBT }\end{array}$} & $27 / 31$ & $4 / 31$ & 0 & $23 / 31$ & $8 / 31$ & 0 \\
\hline & & $28 / 30$ & $2 / 30$ & 0 & $26 / 27$ & $1 / 27$ & 0 \\
\hline & & $28 / 29$ & $1 / 29$ & 0 & $25 / 29$ & $4 / 29$ & 0 \\
\hline & & \multicolumn{3}{|c|}{$p=0.8130^{b}$} & \multicolumn{3}{|c|}{$p=0.3473^{b}$} \\
\hline
\end{tabular}

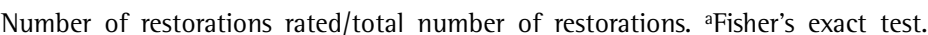
${ }^{b}$ Kruskal-Wallis test $(\mathrm{p}<0.05)$.

\section{Results}

The overall analysis revealed no significant differences ( $p>0.05)$ among groups for up to 12 months in terms of marginal adaptation/ staining and retention (Table 3). The survival analysis did not detect significant differences among the groups regarding retention $(p>0.05)$. Figure 1 shows the
Table 4. Intra-group analysis for each adhesive systems over 12 months

\begin{tabular}{|c|c|c|c|c|c|}
\hline \multirow{2}{*}{$\begin{array}{l}\text { Adhesive } \\
\text { system } \\
\text { group }\end{array}$} & \multirow{2}{*}{$\begin{array}{c}\text { Retention } \\
\mathrm{B} \times 6 \mathrm{M} \times 12 \mathrm{M}\end{array}$} & \multicolumn{2}{|c|}{ Marginal adaptation } & \multicolumn{2}{|c|}{ Marginal staining } \\
\hline & & $\mathrm{B} \times 6 \mathrm{M}$ & $\mathrm{B} \times 12 \mathrm{M}$ & $\mathrm{B} \times 6 \mathrm{M}$ & $\mathrm{B} \times 12 \mathrm{M}$ \\
\hline TSER & $\mathrm{p}=1.000^{\mathrm{a}}$ & $p=0.3173^{b}$ & $p=0.1797^{b}$ & $p=0.0679^{b}$ & ${ }^{*} p=0.0117^{b}$ \\
\hline OSSE & $\mathrm{p}=1.000^{\mathrm{a}}$ & $p=0.1088^{b}$ & ${ }^{*} \mathrm{p}=0.0180^{\mathrm{b}}$ & $p=0.1797^{b}$ & $p=0.3173^{b}$ \\
\hline EWBT & $\mathrm{p}=1.000^{\mathrm{a}}$ & $\mathrm{p}=0.3173^{\mathrm{b}}$ & $p=0.1797^{b}$ & $p=0.3173^{b}$ & $p=0.0679^{b}$ \\
\hline
\end{tabular}

${ }^{a}$ Cochran's test $\mathrm{p} \leq 0.05$. 'Wilcoxon's test. "Significant results. 


\section{Discussion}

Retention is one of the most important criteria for evaluating the longevity of restorations. Considering this fact and according to Kubo et al. (23) and Santiago et al. (24), NCCL restorations are appropriate for evaluating the clinical performance of direct adhesive restorations.

Hydrophilicity of commercially available adhesive systems is a necessary characteristic, especially in clinical application, but it brings along some unfavorable scenario afterwards. This characteristic allows for water sorption and adhesive interface hydrolysis, which causes a significant decrease in adhesion over time $(1,3,18)$. From a laboratory point of view, the EWBT seems to overcome part of this problem $(6,8,20)$.

Several laboratory studies $(4,5,7,21,25)$ demonstrated increased adhesion when dentin is saturated with progressive concentrations of ethanol solutions before the application of bonding agents. The spaces among the collagen fibrils increase, which makes hydrophobic monomer infiltration easier, reducing hydrophilicity of the interface $(6,18,20)$.

EWBT requires the application of increasing concentrations of ethanol solutions on enamel and dentin$$
\text { collagen from collapsing and to replace the total amount }
$$
of water within the demineralized dentin $(3,6,8)$. However, this laboratory procedure takes a long time, which turns the technique clinically unsuitable (8). Therefore, it was necessary to adapt this technique to clinical conditions.

Different dentin saturation times are described in the literature for EWBT, varying from $20 \mathrm{~s}$ to $3.5 \mathrm{~min}$, and the concentration of the ethanol solutions can be gradually increased or applied in a single step $(5-7,18)$. Tay et al. (5) did not observe differences in bond strength between EWBT using one application of 100\% ethanol and conventional etch-and-rinse strategy. On the other hand, Sadek et al. (9) showed poor results when a single application of 100\% ethanol was used. Due to the lack of clinical studies in the literature using EWBT and considering that the main goal of this strategy is to replace the water within the demineralized dentin, the present study adjusted this step using two concentrations (50 and 100\%) of ethanol solutions, which were applied for $20 \mathrm{~s}$ (18), reaching satisfactory laboratory results. Therefore, from now on, the strategy used in this study will be named simplified EWBT, which takes approximately $2 \mathrm{~min}$, compared with approximately $1 \mathrm{~min}$ for the etch-and-rinse technique and $35 \mathrm{~s}$ for the SE protocol.

Another feature that contributes to increase the in vitro interface durability is the reduction of hybrid layer permeability and passage of water through it, achieved by EWBT. This phenomenon reduces the possibility of hydrolytic degradation and promotes long-lasting adhesion $(3,21)$. So far, based on the clinical results of this research, it is not possible to confirm improved durability of restorations by simplified EWBT.

Regarding retention, although a decreasing retention rate $(87.10 \%)$ was observed up to 12 months for the restorations in the OSSE group versus 100\% retention for the TSER group and $93.55 \%$ for the simplified EWBT group, no significant differences could be detected among them (Fig. 1) (Table 3).

One alleged advantage of simplified SE adhesive systems is the associated reduction in the number of clinical steps and low technique sensitivity. In recent years, there has been a trend towards developing SE adhesives that required fewer steps and have decreased $\mathrm{pH}$, taking to increased aggressiveness $(11,14,16)$. However, systems with such combination of features had high hydrophilicity and short shelf lives (12). Hence, the reduced aggressiveness became preferable again. Adper Easy One, used in the present study, has $\mathrm{pH}=2.3$ and is classified according to acidity as a 'mild' OSSE system (14). Less acidic interfaces are less hydrophilic, but 'mild' SE systems exhibit poor demineralization ability, which can be considered a disadvantage, especially when enamel and sclerotic dentin conditioning are considered $(2,12,14)$. Peumans et al. (2) and Dalkilic and Omurlu (13) observed poor clinical performance for the tested OSSE systems.

Enamel acid conditioning prior to the application of mild SE adhesives is mentioned as a method for overcoming these unfavorable characteristics in some studies $(12,13)$. However, this procedure would require an additional step and the modification of the SE approach. In the present investigation, this extra step was not performed, i.e., the adhesion was completely SE-dependent.

The intra-group analysis (Table 4) revealed that the adhesive technique of simplified EWBT group yielded satisfactory results for each evaluated criterion up to one year compared with baseline. The simplified EWBT facilitates adequate hydrophobic monomer infiltration without phase separation $(3,6,22)$. This process takes place as the demineralized dentin is saturated by ethanol, which is a compatible solvent for the monomers. Once a fully interpenetrated hydrophobic layer is formed, the demineralized collagen matrix is better protected against the deleterious actions of water and MMPs $(3,6,18,20,21)$. Despite the short evaluation period, the obtained results encourage testing of this new adhesive technique.

On the other hand, the OSSE group exhibited the worst marginal adaptation when baseline is compared to the 
12-month period. Significant marginal degradation was observed in a short period of time (one year). Although 'mild' SE adhesives are less hydrophilic compared with the 'strong' SE adhesives (16), the absence of a hydrophobic layer, which is present in the other systems, could be partially responsible for the obtained results. The use of a hydrophobic coating in combination with SE systems has been suggested to reduce hybrid layer permeability $(3,10,25)$. Another point to be stressed is the low conditioning capacity of the 'mild' SE adhesives when enamel and sclerotic dentin are the substrates. As mentioned before, the approach chosen for this study was completely SE-dependent, and separate acid etching was not performed, which may have influenced the marginal adaptation results.

Another evaluated criterion was marginal staining, which can result either from superficial imperfections (score B), which may be removed by finishing and polishing instruments, or from a deeper flaw that requires partial or total replacement of the restoration (10). After 1 year, the TSER group presented marginal staining (score B) in $25.81 \%$ of the restorations (8 out of 31 ), which was statistically significant compared to baseline. However, clinical inspection revealed that this staining represented only superficial imperfections.

Some of the features that can be related to marginal staining are overhangs, poor marginal adaptation and caries (1). In this study, however, none of these features could be strictly related to the observed discoloration. As can be seen in Table 4, only 2 out of 31 TSER group restorations were scored $B$ for marginal adaptation. It is likely the thicker interface could be a reason for the high incidence of marginal staining, as the air-thinning step was not applied on the adhesive coat.

As mentioned before, a highly hydrophilic hybrid layer can facilitate interface degradation and subsequent loss of restoration. The results of this study showed that the simplified EWBT behaved similarly to the OSSE and threestep etch-and-rinse strategies, the last one being considered as the gold standard and a reference for clinical studies $(3,4)$. Additionally, the simplified EWBT showed satisfactory individual performance for all evaluated criteria along time, which did not occur when other strategies were analyzed separated for each criteria at the evaluation periods. Therefore, subsequent evaluations should be performed to assess its potential in clinical use.

\section{Resumo}

0 objetivo deste ensaio clínico randomizado foi avaliar o comportamento clínico das restaurações adesivas, usando um adesivo convencional de três passos (CTP), um adesivo autocondicionante de um passo (AUP) e uma técnica simplificada da adesão úmida por etanol (AUET) antes da aplicação de uma resina composta em lesões cervicais não-cariosas. Noventa e três restaurações (31 para cada grupo) foram realizadas em 17 pacientes por um único operador. Nenhum preparo cavitário foi realizado. Depois de 6 e 12 meses, as restaurações foram avaliadas por 2 examinadores previamente treinados, utilizando critérios de Ryge modificados para retenção $(k a p p a=1,00)$ e adaptação/manchamento marginal $(k a p p a=0,81)$, e os resultados foram analisados pelos testes Exato de Fisher e KruskalWallis, respectivamente. Não foram observadas diferenças significativas entre os grupos aos 6 e 12 meses para qualquer um dos critérios avaliados $(p \geq 0,05)$. A análise intra-grupo feita pelos testes 0 de Cochran (para retenção) e Wilcoxon (para adaptação/manchamento marginal) revelou diferenças significativas entre os intervalos de tempo baseline/12 meses para a adaptação marginal no AUP $(p=0,0180)$ e manchamento marginal no $\operatorname{CTP}(p=0,0117)$. A análise de sobrevivência para o critério retenção realizada utilizando o teste de log-rank não apresentou diferenças significantes $(p \geq 0,05)$. As restaurações feitas utilizando a técnica simplificada da adesão úmida por etanol comportaram-se igualmente às outras estratégias adesivas empregadas.

\section{Acknowledgements}

This study was supported by grant from Conselho Nacional de Desenvolvimento Científico e Tecnológico (CNPq). The authors would like to thank the volunteer's participation.

\section{References}

1. Breschi L, Mazzoni A, Ruggeri A, Cadenaro M, Di Lenarda R, Dorigo ES. Dental adhesion review: aging and stability of the bonded interface. Dent Mater 2008;24:90-101.

2. Peumans $M$, Kanumilli $P$, De Munck J, Van Landuyt $K$, Lambrechts $P$, Van Meerbeek B. Clinical effectiveness of contemporary adhesives: a systematic review of current clinical trials. Dent Mater 2005;21:864881.

3. Liu Y, Tjäderhane L, Breschi L, Mazzoni A, Li N; Mao J, et al.. Limitations in bonding to dentin and experimental strategies to prevent bond degradation. J Dent Res 2011;90:953-968.

4. Sadek FT, Castellan CS, Braga RR, Mai S, Tjäderhane L, Pashley DH, et al.. One-year stability of resin-dentin bonds created with a hydrophobic ethanol-wet bonding technique. Dent Mater 2010;26:380-386.

5. Tay FR, Pashley DH, Kapur RR, Carrilho MRO, Hur YB, Garrett LV, et al.. Bonding BisGMA to dentin - a proof of concept for hydrophobic dentin bonding. J Dent Res 2007;86:1034-1039.

6. Guimaraes LA, Almeida JCF, Wang L, D'alpino PHP, Garcia FCP. Effectiveness of immediate bonding of etch-and-rinse adhesives to simplified ethanol-saturated dentin. Braz Oral Res 2012;26:177-182.

7. Hosaka K, Nishitani Y, Tagami J, Yoshiyama M, Brackett WW, Agee KA, et al.. Durability of resin-dentin bonds to water- vs. ethanol-saturated dentin. J Dent Res 2009;88:146-151.

8. Osorio E, Toledano M, Aguilera FS, Tay FR, Osorio R. Ethanol wet-bonding technique sensitivity assessed by AFM. J Dent Res 2010;89:1264-1269.

9. Sadek FT, Mazzoni A, Breschi L, Tay FR, Braga RR. Six-month evaluation of adhesives interface created by a hydrophobic adhesive to acidetched ethanol-wet bonded dentine with simplified dehydration protocols. J Dent 2010;38:276-283.

10. Loguercio AD, Manica D, Fernanda F, Grande CZ, Amaral R, Stanislawczuk $R$, et al.. A randomized clinical evaluation of a one- and two-step self-etch adhesive over 24 months. Oper Dent 2010; 35:265272.

11. Mozsner N, Salz U, Zimmermann J. Chemical aspects of selfetching enamel-dentin adhesives: a systematic review. Dent Mater 2005;21:895-910.

12. Van Meerbeek B, Yoshihara K, Yoshida $Y$, Mine A, De Munck J, Van Landuyt KL. State of the art of self-etch adhesives. Dent Mater $2011 ; 27: 17-28$.

13. Dalkilic EE, Omurlu H. Two-year clinical evaluation of three adhesive systems in non-carious cervical lesions. J Appl Oral Sci 2012;20:192199.

14. Silva e Souza Jr MH, Carneiro KGK, Lobato MF, Silva e Souza PAR, Góes 
MF. Adhesive systems: important aspects related to their composition and clinical use. J Appl Oral Sci 2010;18-3:207-214.

15. Susin AH, Vasconcelos WA, Saad JRC, Oliveira Jr. OB. Tensile bond strength of self-etching versus total-etching adhesive systems under different dentinal substrate conditions. Braz Oral Res 2007;21:81-86.

16. Van Meerbeek B, De Munck J, Yoshida Y, Inoue S, Vargas M, Vijay $P$, et al.. Adhesion to enamel and dentin: current status and future challenges. Oper Dent 2003;28:215-235.

17. Chermont $A B$, Carneiro KK, Lobato MF, Machado SMM, Silva e Souza Jr $\mathrm{MH}$. Clinical evaluation of postoperative sensitivity using self-etching adhesives containing glutaraldehyde. Braz Oral Res 2010;24:349-354.

18. Nishitani Y, Yoshiyama M, Donnelly AM, Agee KA, Sword J, Tay FR, et al.. Effects of resin hydrophilicity on dentin bond strength. J Dent Res 2006;85:1016-1021.

19. Pashley DH, Tay FR, Carvalho RM, Rueggeberg FA, Agee KA, Carrilho $\mathrm{MRO}$, et al.. From dry bonding to water-wet bonding to ethanol-wet bonding. A review of the interactions between dentin matrix and solvated resins using a macromodel of the hybrid layer. Am J Dent 2007;20:7-21.

20. Pashley DH, Tay FR, Breschi L, Tjäderhane L, Carvalho RM, Carrilho MRO, et al.. State of the art etch-and-rinse adhesives. Dent Mater 2011;27:116.
21. Cadenaro M, Breschi L, Rueggeberg FA, Agee K, Di Lenarda R, Carrilho $\mathrm{MRO}$, et al.. Effect of adhesive hydrophilicity and curing time on the permeability of resins bonded to water vs. ethanol-saturated acidetched dentin. Dent Mater 2009;25-1:39-47.

22. Shin TP, Yao X, Huenergardt R, Walker MP, Wang Y. Morphological and chemical characterization of bonding hydrophobic adhesive to dentin using ethanol wet bonding technique. Dent Mater 2009;25:1050-1057.

23. Kubo S, Kawasaki K, Yokota H, Hayashi Y. Five-year clinical evaluation of two adhesive systems in non-carious cervical lesions. J Dent 2006;34:97-105.

24. Santiago SL, Passos VF, Vieira AHM, Navarro MFL, Lauris JRP, Franco EB. Two-year clinical evaluation of resinous restorative systems in non-carious cervical lesions. Braz Dent J 2010;21-3:229-234.

25. Sadek FT, Pashley DH, Ferrari M, Tay FR. Tubular occlusion optimizes bonding of hydrophobic resins to dentin. J Dent Res 2007;86:524-528.

Received December 17, 2012 Accepted May 17, 2013 